\title{
SOLUTION OF TIME-SPACE FRACTIONAL BLACK-SCHOLES EUROPEAN OPTION PRICING PROBLEM THROUGH FRACTIONAL REDUCED DIFFERENTIAL TRANSFORM METHOD
}

\author{
Manzoor Ahmad*, Rajshree Mishra And RENU JAIN
}

\begin{abstract}
Mathematical model introduced by Black and Scholes express financial derivatives more significantly. This model with fractional derivatives resulting in fractional Black-Scholes (B-S) equation express financial problems in a better way. In this paper, we introduce the fractional reduced differential transform method (FRDTM) to solve the time-space fractional BlackScholes equation executing European options. This method is a modified version of the original differential transform method (DTM). This method proves to be valid for solving time-space Black-Scholes equation as it reduces the computational work to a greater extent. Moreover, this method helps in finding the solution without linearization or discretization. The efficiency of the method is tested by solving certain examples. The proposed mathematical representation can be useful to understand and solve time-space fractional differential equations arising in financial mathematics and other related fields.
\end{abstract}

Mathematics subject classification (2020): 91G20, 91G30, 91G80, 35Q91.

Keywords and phrases: fractional time-space Black-Scholes equation; fractional derivatives; fractional reduced differential transform method; European option pricing; Mittag-Leffler function.

\section{REFERENCES}

[1] F. BLACK, M. Scholes, The pricing of options and corporate liabilities, J. Polit. Econ. 81, 3 (1973), 637-354.

[2] L. S. JiAng, C. L. Xu, X. M. Ren, Mathematical Model and Case Analysis of the Pricing of Financial Derivatives, Higher Education Press, Beijing 2008.

[3] Y. KwOK, Mathematical Models of Financial Derivatives, 2nd edn. Springer, Berlin, 2008.

[4] C. B. ZENG, Y. Q. Chen, Q. G. YANG, Almost sure and moment stability properties of fractional order Black-Scholes model, Fract. Calc. Appl. Anal. 16, 2 (2013), 317-331.

[5] W. Wyss, The fractional Black-Scholes equations, Frac. Calc. Appl. Anal. 3, 1 (2000), 51-61.

[6] A. Cartea, D. Del-Castillo-Negrete, Fractional diffusion models of option prices in markets with jumps, Phys. A, Stat. Mech. Appl. 374, 2 (2007), 749-763.

[7] L. MEng, M. WANG, Comparison of Black-Scholes formula with fractional Black-Scholes formula in the foreign exchange option market with changing volatility, Asia-Pac. Financ. Mark. 17, 2 (2010), $99-111$.

[8] G. JUMARIE, Derivation and solutions of some fractional Black-Scholes equations in coarse-grained space and time. Application to Merton's optimal portfolio, Comput. Math. Appl. 59, 3 (2010), 11421164.

[9] G. JUMARIE, Stock exchange fractional dynamics defined as fractional exponential growth driven by Gaussian white noise. Application to fractional Black-Scholes equations, Insur. Math. Econ. 42, 1 (2008), 271-287.

[10] S. L. Heston, A Closed-Form Solution for Options with Stochastic Volatility with Applications to Bond and Currency Options, Rev. Financial Stud. 6, 2 (1993), 327-343.

[11] P. Tankov, R. ConT, Financial Modelling with Jump Processes, Chapman \& Hall/CRC Financial Mathematics Series, Taylor \& Francis, 2003. 
[12] G. BARles, H. M. Soner, Option pricing with transaction costs and a nonlinear Black-Scholes equation, Finance Stoch. 2, 4 (1998), 369-397.

[13] Y. Li, X. YAng, S. Sun, A class of intrinsic parallel difference methods for time-space fractional Black-Scholes equation, Advances in Difference Equations, (2018), 2018:280.

[14] Y. Xiaozhong, W. Lifei, S. Shuzhen, Z. Xue, A universal difference method for time-space fractional Black-Scholes equation, Adv. Differ. Equ. (2016), 2016:71.

[15] S. Kumar, D. Kumar, J. Singh, Numerical computation of fractional Black-Scholes equation arising in financial market, Egy. J. basic Appl. Sci. 1, 3-4 (2014), 177-183.

[16] D. Lu, J. Wang, M. Arshad, Abdullah, A. Ali, Fractional Reduced Differential Transform Method for Space-Time Fractional Order Heat-Like and Wave-Like Partial Differential Equations, J. Adv. Phys. 4, 4 (2017), 598-607.

[17] K. Diethelm, The Analysis of Fraction Differential Equations, Springer, Berlin 2010.

[18] R. Hilfer, Applications of fractional calculus in physics, Word Scientific Company, Singapore, 2000.

[19] B. L. Guo, X. K. Pu, F. H. HuAng, Fractional Partial Differential Equations and Their Numerical Solutions, Science Press, Beijing 2011 (in Chinese).

[20] M. H. Akrami, G. H. ERJAeE, Examples of Analytical Solutions by means of Mittag-Leffler Function of Fractional Black-Scholes Option Pricing Equation, Frac. Calc. Appl. Anal. 18, 1 (2015), 38-47.

[21] M. A. M. Ghandehari, M. RanjBar, European Option Pricing of Fractional Version of the BlackScholes Model: Approach Via Expansion in Series, Int. J. Nonlinear Sci. 17, 2 (2014), 105-110.

[22] S. Kumar, A. Yildirin, Y. Khan, H. Jafari, K. Sayevand, L. Wei, Analytical Solution of Fractional Black-Scholes European Option Pricing Equations Using Laplace Transform, J. Fractional Calc. \& Appl. 2, 8 (2012), 1-9.

[23] A. S. V. RaVi Kanth, K. Aruna, Solution of time fractional Black-Scholes European option pricing equation arising in financial market, Nonlinear Eng. 5, 4 (2016), 269-276.

[24] J. K. ZHOU, Differential transformation and its applications for electrical circuits, Wuhan: Huazhong University Press, 1986.

[25] A. S. V. RaVi KAnth, K. ARUnA, Two-dimensional differential transform method for solving linear and non-linear Schrodinger equations, Chaos Solitons Fractals, 41, (2009), 2277-2281.

[26] C. K. Chen, S. H. Ho, Solving partial differential equations by two-dimensional differential transform method, Appl. Math. Comput. 106, (1999), 171-179.

[27] Z. M. ODIBAT, Differential transform method for solving Volterra integral equations with separable kernels, Math. Comput. Model. 48, 7-8 (2008), 1141-1149.

[28] S. A. Ahmed, T. M. Elzaki, A Comparative Study of Sumudu Decomposition Method and Sumudu Projected Differential Transform Method, World Appl. Sci. J. 31, 10 (2014), 1704-1709.

[29] B. JANG, Solving linear and nonlinear initial value problems by the projected differential transform method, Comput. Phys. Commun. 181, (2010), 848-854.

[30] F. Mainardi, On the Initial Value Problem for the Fractional Diffusion-Wave Equation, in: S. Rionero, T. Ruggeeri, Waves and Stability in continuous media, World Scientific, Singapore, (1994), 246-251.

[31] M. Dalir, Applications of Fractional Calculus, App. Math. Sci. 4, 21 (2010), 1021-1032.

[32] I. Podlubny, Fractional Differential Equations, Academic Press, San Diego, 1999.

[33] A. M. Mathai, H. J. Haubold, An Introduction to Fractional Calculus, Nova Science Publishers, New York, 2017.

[34] M. CAputo, Elasticita e Dissipazione, Bologna, Zani-Chelli, 1969.

[35] G. M. Mittag-Leffler, Sur La Representation Analytique d'une branche Uniforme d'une Function Mogene, Acta Math. 29, (1905), 101-181.

[36] A. Wiman, Uber den Fundamental Satz in Der Theorie Der Funcktionen, Ea(x), Acta Math. 29, (1905), 191-201.

[37] S. Momani, Z. Odibat, V. S. ERturk, Generalized differential transform method for solving a space and time fractional diffusion wave equation, Phys. Lett. A 370, 5-6 (2007), 379-87.

[38] Z. Odibat, S. Momani, A generalized differential transform method for linear partial differential equations of fractional order, Appl. Math. Lett. 21, 2 (2008), 194-99.

[39] M. MagdziarZ, Black-Scholes Formula in Subdiffusive Regime, J. Stat. Phys. 136, (2009), $553-564$. 